\title{
What does the research evidence base tell us about the use and impact of sustainability pedagogies in initial teacher education?
}

\author{
Many sustainability education scholars argue that active, participatory and \\ experimental pedagogies, known as sustainability or ESD pedagogies, provide \\ the most effective strategies for developing learners' understanding, thinking and \\ ability to act for sustainability. However, factors that impact learning are \\ complex and the extent to which some pedagogies are more effective than others \\ for promoting student learning is contested. The work on sustainability \\ pedagogies has tended not to be problematized. This paper interrogates the \\ literature on sustainability pedagogies in initial teacher education to determine \\ the extent to which the current level of evidence supports pedagogical \\ assumptions held by sustainability education scholars. The findings suggest that \\ factors that impact student teacher learning for sustainability require additional \\ exploration in order to draw reliable conclusions and inform pedagogical \\ decisions that can best support the development of prospective teachers' \\ understanding, thinking and ability to employ sustainability pedagogies.
}

Keywords: sustainability pedagogies; ESD pedagogies; initial teacher education, pre-service teacher education

\section{Introduction}

Embedding sustainability education in pre-service teacher education is as much about paying attention to pedagogy as it is about addressing the curriculum (Eilam and Trop 2011). On pedagogy, Sterling (2012) argues that there is broad consensus among experts that sustainability education requires 'active, participatory and experiential learning methods that engage the learner and make a real difference to the learner's understanding, thinking and ability to act' (p. 36). Such methods are often referred to as sustainability pedagogies (Cotton and Winter 2010; Sterling 2012) and ESD pedagogies (McKeown 2012) and are underpinned by an assumption that preparing students to effectively manage emergent sustainability issues such as climate change, biodiversity loss and increasing social inequality requires new ways of teaching and learning. It is 
argued that traditional transmissive approaches such as lecturing and demonstrations, while effective for presenting information, limit learners' understanding, thinking and capacity to act for sustainability (Segalàs, Mulder, and Ferrer-Balas 2012; Sterling 2012). Sustainability pedagogies, then, are said to promote a set of alternative, interactive and discursive teaching methods believed to be more effective at building capacity for sustainability than traditional didactic approaches (Cotton \& Winter, 2010; Sterling, 2004, 2012; Tilbury and Cooke, 2005). For Cotton and Winter (2010) such methods include role play and simulations, group discussions and dialogue, stimulus activities, debates, critical incidents, case studies, reflexive accounts, personal development planning, critical reading and writing, problem-based learning, and fieldwork. To this list, Sterling (2012) adds dairying, modelling good practice, futures visioning, worldview and values research, and action research.

However, as Education academics, we are aware the factors that impact student learning are complex. In line with Westwood (2008), we contend that there is no silver bullet for teaching and learning in sustainability education. Progress in student learning is not linear and can be affected by a variety of developmental, cultural, contextual and other forces (Clarke and Pittaway 2014). Given that education is critical to overcoming high stakes sustainability issues (Barth, Michelsen, and Rieckmann 2016) and the potentially important role of pedagogy within that, we wondered about the extent to which the concept of sustainability pedagogies is supported through empirical research: What evidence is there that sustainability pedagogies provoke the sort of learning known as education for sustainability (EfS) (Sterling 2012), also known as education for sustainable development (ESD). For teacher educators working to teach or embed EfS into teaching and learning, it is important that pedagogical decisions are based on reliable research. If the pedagogies being promoted and used are not known through 
research evidence to positively impact on pre-service teachers' overall capacity for understanding and teaching about and for sustainability, there may be a need to rethink our understandings of effective approaches and actions.

The objective of our research, then, is to interrogate the extent to which current levels of evidence support the assumption that sustainability pedagogies facilitate learning that makes a real difference to pre-service teachers' understanding, thinking and ability to act for sustainability, hereon referred to as learning for sustainability. In other words, what evidence is there that sustainability pedagogies influence learning outcomes to the point that pre-service teachers are enabled to make changes for or towards sustainability? If so, what sort of change? Is the evidence robust enough to support wide-scale adoption of a specific set of pedagogies for the teaching of EfS? A second objective is to develop understanding of the considerations, opportunities and/or challenges to pre-service teacher learning for sustainability that emerge from the use of sustainability pedagogies. An understanding of facilitating factors and challenges that may promote or discourage EfS is important if teacher education is to effectively contribute to the preparation of teachers capable of addressing EfS once in schools. Although the focus in this paper is on initial teacher education, pedagogy is relevant to all educators. Hence, we consider that the specifics of the effectiveness of EfS pedagogies investigated here are transferable and may be helpful to academics beyond teacher education, who are either teaching into a sustainability course or embedding EfS into a course. This work, then, is led by three research questions:

- What pedagogical strategies are being used by teacher educators for the teaching of education for sustainability (EfS) or education for sustainable development (ESD)? 
- What is the impact of sustainability pedagogies on student teacher learning for sustainability?

- What opportunities, challenges or considerations emerge from the application of sustainability pedagogies and how do these enhance or detract from student teacher learning for sustainability?

We begin by outlining the conceptual background and methods of the study, then present the findings before returning to discuss questions raised above to consider implications for the field of EfS or ESD through two propositions and a recommendation.

\section{Conceptual background}

While the idea of sustainability pedagogies is not disputed by EfS scholars, the broader literature on pedagogy is highly contradictory and contested. For some, pedagogy is about the delivery of information. For others, it is a complex interplay between the teacher and the learner (Loughran 2013; Wink 2010). Within the field of EfS, pedagogy is concerned with transformational learning (Blake, Sterling, and Goodson 2013; Sterling 2010-11). Transformational learning goes beyond an acquisition of knowledge and an understanding of concepts and seeks instead to make profound changes to learners' understandings, skills, values, attitudes and dispositions in ways that will ultimately lead to both personal and social transformation (Mezirow 2000; Mezirow 2009; Sterling 2010-11; Sipos, Battisti, and Grimm 2008). The goal is to effect the sort of change in learning that Sterling (2010-11) calls epistemic or third-order learning.

Pedagogy in EfS is also political. Pedagogical approaches are underpinned by varying epistemologies, ontologies, ideologies and values, and, thus, mean different things to different people and can serve as tools for differing purposes (see Littledyke 
and Manolas, 2010). Eilam and Trop (2011) and Christie et al., (2013) have traced the complexities of sustainability pedagogies. While it appears that academics overwhelmingly support uptake of active, student-centred pedagogies for the teaching of sustainability (Christie et al. 2013), a lack of clear guidelines for 'how to' is offputting (Eilam and Trop, 2011).

Sustainability pedagogies are borne out of research findings that learning about the environment or environmental problems does not lead to action for sustainability (Hines, Hungerford, and Tomera 1987; Hungerford and Volk 1990; Marcinkowski 2004; Cotton and Winter 2010; Lotz-Sisitka et al. 2015) or transformative personal and/or social change (Sipos et al., 2008; Sterling, 2011). For example, knowledge about the environmental impact of single use plastic bags does not necessarily stop people using these as rubbish bin liners, nor does it necessarily lead to people using more environmentally friendly options. Proponents of sustainability pedagogies argue that the complexities of existential threats such as climate change necessitate replacing didactic, transmissive pedagogies such as lectures and rote learning with more integrative problem-solving, action-oriented methods capable of broaching topics in meaningful, open-ended ways (Amster 2014; Lotz-Sisitka et al. 2015). It is argued that understanding and building capacity to take action for multi-dimensional sustainability issues requires constructivist pedagogies that actively engage students' 'head, hands and heart' (Sipos, Battisti, and Grimm 2008, 75) through place-based, democratic, collaborative and active strategies (Sterling 2012; Littledyke and Manolas 2010). Such strategies are believed to be more effective than others for encouraging the type of transformational or 'third order' learning (Sterling 2010-11, 25) required for learning for sustainability. 
Pedagogy, nevertheless, has many meanings and perspectives (Loughran 2013; Clarke and Pittaway 2014) and the extent to which any one set of pedagogical approaches and strategies are more effective than others in promoting student learning is contested. For example, there are arguments for and against explicit instruction approaches that favour lecture and demonstration style teaching methods. Proponents argue that explicit instruction is at least as effective as any other teaching and learning approach (Curzon 1997; Eggen and Kauchak 2012) and has a strong history of empirical evidence to support its effectiveness (Killen 2007; McMullen and Madelaine 2014; Hollingsworth and Ybarra 2009). On the other hand, there is a strong body of research criticising explicit instruction for lacking consideration of learner diversity and learning contexts (Laurillard 2002; Luke 2014). From our perspective, the question is not what are the most effective pedagogy/ies, but rather most effective for what?

Hence, different perspectives on pedagogy need to be taken into account. While there are many different approaches, they are often grouped along a continuum representing two general orientations. At one end of the continuum is positivism, where the educator will approach teaching and learning activity from an objective, 'value-free' stance (Christie et al. 2013) which translates into pre-designed, non-negotiable, systemic behavioural goals, outcomes and activities. Students are told what and how they will be learning, and what they have to do and show in order to demonstrate stated outcomes (Luke 2014). The underpinning assumption is that learning can be isolated from any other variable or influencing factors and, thereby, it is possible to have one valid or effective pedagogical approach that works for all students across all subjects and contexts. The second orientation is called postpositivism or interpretivism. Here the educator still pre-designs goals, outcomes and activities, but allows flexibility for individual interpretation and deviation in response to learner subjectivities, individual 
insights, prior experiences and developments during the teaching phase or in-themoment events (Littledyke and Manolas 2010). The underpinning assumption is that effective teaching responds to context and learner needs.

In reality there are no formal mechanisms for locking specific pedagogical methods to any one particular orientation. Teaching does not ascribe to a linear and causal relation and categorising pedagogy, in itself, is not necessarily useful as it ignores the complexity of teaching and learning and limits capacity to further develop pedagogical understanding (Kelly 2013). We take the position that there are many different (existing and novel) approaches to teaching and learning and effective teachers draw from a broad range of pedagogies as the situation demands (Killen 2015).

Whatever the case, there appears to be agreement among scholars that higher education works against implementation of constructivist pedagogies (Seatter and Ceulemans 2017; Wiek et al. 2014). However, it is our experience that examples can be found where constructivist pedagogies are implemented for teaching and learning of sustainability within higher education. Some academics write from within their disciplines by, for instance, telling about the use of concept maps for including EfS in Engineering education (Svanström et al. 2017). Segalàs, Ferrer-Balas and Mulder (2010) write about application of a variety of strategies in engineering courses ranging from workshops to role play, project-based learning, and film viewing and analysis. Other scholars take a more general approach by, for example, offering a range of case study types that are applicable for the embedding of sustainability across a range of disciplines (Sprain and Timpson 2012) and highlighting the use of problem- and project-based learning across a discipline (Wiek et al. 2014). Ceulemans and De Prins (2010), provide a comprehensive manual that provides a broad range of strategies such 
as brainstorming, jigsaw, dialogue, team work and problem-oriented education, alongside instructions for how to apply the strategies.

In summary, across higher education, there appears to be support for and examples of the adoption of postpositivist approaches for the teaching of sustainability education. However, scholars argue that, in practice, adoption is low (Seatter and Ceulemans 2017; Juárez-Nájera, Dieleman, and Turpin-Marion 2006). What is also not well understood is the effectiveness of these approaches on student learning. As Rickinson argued in his seminal (2001) paper, we lack both large scale and longitudinal studies about student learning in the field. Our intent in this paper is to explore whether that situation has changed by examining the type of approaches deployed by teacher educators and the extent to which these pedagogies are deemed in the literature to be effective for student learning for sustainability.

\section{Method}

This research is guided by the systematic review method. A systematic review attempts to collate all empirical evidence that fits pre-specified eligibility criteria in order to answer a specific research question. It uses explicit, systematic methods that are selected with a view to minimising bias to provide reliable findings from which conclusions can be drawn and decisions made (Oxman and Guyatt 1993). Systematic reviews are particularly helpful for mapping out areas of uncertainty or where 'spurious certainty abounds' (Petticrew and Roberts 2006, 2). In the case of sustainability pedagogies, broad-scale theorising gives the appearance that we know a lot, however, we wonder about the basis for the knowledge and question whether it has a basis in evidence or assumption, and whether and how that relates to teacher education.

This review is based on the recommendations of preferred reporting items for systematic review and meta-analysis protocols (Shamseer et al. 2015), summarised in 
Figure 1. We were aware that research on EfS, pedagogy and teacher education can span across various discipline areas, relevant publications can appear in a number of different journals indexed in various databases and that databases have different rules concerning syntax and types of search terms, truncation rules, and limiters. Therefore, a preliminary scoping search was conducted in consultation with the University's social science librarian. This involved searching the University's database sets to compile a list of the most applicable databases and a search string capable of providing the most relevant studies. The final search for eligible studies was undertaken using Eric (ProQuest), Informit A+ Education, Informit Education Collection, ProQuest Education, PsychINFO, Sage Journals and Scopus using the following terms in the title, abstract, paper or keywords: initial teacher education, teacher education, pre-service teacher education, student teacher AND sustainability pedagog*, EfS pedagog*, ESD pedagog*, environmental education AND pedagog*. Search strings were customised to suit each of the selected databases and searches were limited to peer reviewed journal articles published in English prior to 2018. Publications were included if the publication was focused on pedagogy, EfS and initial teacher education; was a peer reviewed journal article and conference paper; and was written in English. Publications not meeting this criteria were deleted. For example, the publication was deleted if the research concerned EfS pedagogies in a discipline area other than teacher education, if the research was about curriculum design or implementation of a particular approach to the teaching and learning for sustainability, or about integrating sustainability education generally. Additional studies were included, as identified by us, by hand searching reference lists of the publications included and from our own background in the field (e.g., Author et al, 2017). We acknowledge that publications drawn from the authors' knowledge of the field does limit the scope of potential further relevant studies and that 
consultation with scholars in the field and grey literature searches may have yielded further publications.

Figure 1 summarises the research process. Our search identified 559 potential publications (step 1). After removal of duplication (step 2), 509 titles and abstracts were downloaded and screened by the first author to determine suitability, resulting in the inclusion of 30 publications and exclusion of 479 publications (step 3). At this stage, inter-rater reliability was assured through discussions between the two authors. This involved the second author independently assessing 20 per cent of included and 10 per cent of excluded publications according to the criteria. We then met to discuss categorisations and align understandings. Initially, inter-rater reliability was 67 per cent for included studies and $83 \%$ for excluded studies (step 4). After a number of meetings to further discuss original categorisations and align understandings, it was determined that 30 full-text publications be assessed for eligibility. This resulted in the exclusion of a further 21 publications (step 5). After identification and inclusion of a further eight publications, (step 6), a total of 17 publications were finally included in the study (step 7).

\section{Embed Figure 1 here}

The systematic review approach is useful for interrogating what has been studied and found in emerging and diverse areas of research (Guitart, Pickering, and Byrne 2012), such as the intersection of EfS, pedagogy and teacher education. Nevertheless, it is important to note that the approach has limitations. There is a risk of publication bias resulting from sole use of peer-reviewed studies. Studies that lack statistical significance are often unpublished and, thereby, can skew available reviews and distort understandings of the construct of interest (Valentine et al. 2011). To mediate this 
problem and extend the findings of this review, future research can investigate the aims of this research using a larger pool of studies (Bowles and Brindle 2017), including, for example, grey literature and unpublished $\mathrm{PhD}$ studies. It can also be difficult to combine and compare findings from the different studies because researchers have adopted different investigation methods (MacGill, 2019). However, we propose that a focus on comparison alone overlooks important aspects of process and other factors like enablers and constraints. Finally, we acknowledge that limitations also result from information provided or omitted by the authors of the studies.

\section{Findings}

The findings are organised around the research questions. For each question, we report on the findings of our analysis then, where appropriate, highlight key insights as related to the research question.

\section{What pedagogical strategies are being used by teacher educators for the teaching of sustainability?}

In seeking to answer this first question, we classified pedagogical strategies according to Sterling's (2012) pedagogical methods and Sipos et al's (2008) heads, hands and hearts evaluation framework. As explained above, Sterling (2012), building on Cotton and Winter (2010), promotes a set of strategies or methods for the teaching and learning of sustainability (role play and simulations, group discussions and dialogue, stimulus activities, debates, critical incidents, case studies, reflexive accounts, personal development planning, critical reading and writing, problem-based learning, and fieldwork, dairying, modelling good practice, futures visioning, worldview and values research, and action research). Sipos et al., (2008) provide a framework to classify

educational learning objectives. The head constituent refers to cognition and thinking, 
the hands to activity and doing, and the heart to emotion and feelings. Sipos et al., (2008) argue that paying attention to all three domains results in a more transformative educational experience (Cotton \& Winter, 2010). We were pleasantly surprised to find that teacher educators in the sample of studies interrogated apply a comprehensive range of pedagogical strategies beyond Sterling's (2012) framework and also draw from Sipos et al's., (2008) three domains for the teaching and learning of sustainability.

Teacher educators in our sample applied a total of 15 from 16 methods named by Sterling (2012). Group discussions and dialogue were equally the most common methods (11 publications), followed by fieldwork (7 publications); modelling good practice and critical reading and writing (6 publications); reflexive accounts (5 publications); role plays and simulations, stimulus activities, critical incidents and problem-based learning (3 publications); debates, dairying, futures visioning and worldview and values research (2 publications); and action research (1 publication). Further, each teacher educator reported applying at least two methods to a maximum of seven. For example, Hug (2010) provides an auto-ethnographic account to explain how he modelled read-aloud strategies and used critical reading to build student teachers' environmental content knowledge and children's literature evaluation skills. Five authors (Preston and Griffiths 2004; Kennelly and Taylor 2007; Nicholas, Oulton, and Scott 1993; Paige, Lloyd, and Chartres 2008; Preston 2011) reported using as many as four different methods each for teaching EfS. In all, case study was the only pedagogical method not applied by any author whose work was reviewed for this study.

Teacher educators also applied pedagogical methods that reach beyond Sterling's (2012) framework. This includes worksheets (America 2014), graphic organisers (Richardson, Liang, and Wake 2014) including concept mapping (Aleixandre and Gayoso 1996), lectures (Stewart and Muller 2009), brainstorming (Aleixandre and 
Gayoso 1996), thinking hats (Jenkins 1999/2000) and peer teaching (Kennelly, Taylor, and Maxwell 2008).

In exploring the extent to which strategies used by teacher educators to address EfS aligns with Sipos et al's., (2008) 'head, hands and heart' domains, we found that 10 out of the 17 authors addressed all three domains in the work reported. Unsurprisingly, the cognitive (head) domain was the most common, addressed by all authors. This was followed by the affective (heart) domain (15 authors) and psychomotor (hand) domain (11 authors).

Based on the evidence provided in this study's 17 papers, it can be extrapolated that the teacher educators whose work we reviewed apply a broad range of pedagogical strategies in attempting to expand student learning for sustainability. Notable, however, is that very few of the publications go beyond a descriptive mention or naming of pedagogy/ies applied. We propose that it is easy for teacher educators to ascribe a name to what they do in class, after all pedagogy is a central specialism pertaining to Education. It is much harder to provide an analysis of the practices and issues that arise with a view to providing evidence of effectiveness or impact.

\section{What is the impact of sustainability pedagogies on student teacher learning for sustainability?}

We sought to establish the impact of pedagogical methods used by teacher educators on student learning for sustainability. However, discerning the impact of sustainability pedagogies on student teacher learning for sustainability was not straight forward. Not all authors addressed student learning. For example, Aleixandre and Gayoso (1996) describe how they embed environmental education into a science methods course and provide a clear overview of the pedagogical methods used, but focus outcomes and discussion on issues other than student learning. In other cases, outcomes related to 
student learning as a consequence of applying sustainability pedagogies were vague or provided unconvincing supporting evidence. For instance, Nicholas, Oulton and Scott (1993) make a point of emphasising that their use of experiential methods set out to enable and equip students to counter passive teaching approaches, but provide no evaluation of the methods. Similarly, Hug (2010) argues for the effectiveness of using classroom discussion and book critique strategies, but provides no supporting evidence.

In total, we were able to identify outcomes related to student learning in 10 publications. Sterling's (2011) levels of learning provided us with a framework for organising our analysis:

- First-order learning: Refers to learning focused on increasing knowledge and/or awareness. For example, after a lesson on plastic waste, a learner may be able to explain the extent to which plastic waste is problematic, but feel unmotivated to make or effect any change.

- Second-order learning: Refers to learning that changes the learner's beliefs, values, assumptions and ways of doing things. Here, in the same example as above, the learner may critically analyse the problem to consider values and ethics of plastic waste, and what can be done to change the situation.

- Third-order learning: Refers to learning that shifts the learner's epistemology. In the case of the plastic waste lesson, learning may effect profound changes in the learner's thinking, values and practices related to waste. Third-order learning is what is commonly defined as transformative and as learning for sustainability. Unsurprisingly, all of the ten publications reported learning of the first order such as raised student awareness about consumption, waste and recycling (America 2014), enhanced knowledge about local species (Jagger, Sperling, and Inwood 2016) 
and understanding about teaching principles (Prescott 2016), ecoliteracy and experiential learning (Burke and Cutter-Mackenzie 2010). Four studies (America 2014; Preston 2011; Burke and Cutter-Mackenzie 2010; Collins-Figueroa 2012; Preston and Griffiths 2004) additionally reported second order learning. This includes enhanced consciousness of own consumption habits (America, 2014), critical thinking leading to a re-shaping of environmental ethics and consciousness (Preston, 2011), applying critical thinking to overcome barriers to the teaching of biodiversity (Collins-Figueroa, 2012) and increased connections to place and improved ability to express feelings (Preston \& Griffith, 2004). No authors reported provoking third order learning, even when the learning is intentionally designed to provoke change for sustainability (e.g., Nicholas, Oulton, and Scott 1993). This last point speaks to a complex conceptualisation-practice gap, as well as the complex nature of teaching and learning. Research finds most academics claim higher order thinking is an objective of their courses, but analysis of academics' actual teaching and assessment practices contradict or work against such (ambitious) objectives (Lemons and Lemons 2013). Effecting third order learning is more complex than just planning for it. Students' responses to course aims are affected by a broad range of influences, including, for example, epistemological beliefs, approaches to learning, motivations or attitudes (Lee and Choi 2017). Worth noting, also, is that authors provide no details on the timing of the learning evaluations. Considering research findings that the effects of education interventions diminish over time (Redman and Redman 2017; Hungerford and Volk 1990; Redman 2013) we wonder about the extent to which findings in the studies are supported over time. 


\section{What opportunities, challenges or considerations emerge from the application of sustainability pedagogies and how do these enhance or detract from student teacher learning for sustainability?}

We were interested in investigating peculiarities or specifics related to challenges, opportunities or considerations for student learning related to the application of sustainability pedagogies. In this we were also challenged. All authors outlined pedagogical methods applied across their subject or course, but only four (Preston 2011; Preston and Griffiths 2004; Aleixandre and Gayoso 1996; Collins-Figueroa 2012) provided details on challenges related to applying sustainability pedagogies. Aleixandre and Gayoso (1996) and Collins-Figueroa (2012) write about the well-known problems of limited time and training. Preston (2011) writes about the personal challenge of resisting the temptation to provide students with 'answers and a moral agenda' (p. 377). Preston and Griffith highlight a number of pedagogical dilemmas related to teaching in transformative ways. This includes the difficulties of teaching through a collaborative action research approach, enabling students to transfer learning beyond an immediate experience, and effectively challenging students' ontological underpinnings.

We also investigated opportunities or considerations for learning, as reported by authors. A little over half (11 out of 17) of the publications provided some explanation about how the applied pedagogies facilitated learning. It is notable that most of the learning reported is of the first order type, but also positive that there is some evidence of second order learning among some of the articles, at least in the short term. For instance, videos (America 2014), group activities (Hug 2010) and hands-on and placebased activities (Jagger, Sperling, and Inwood 2016; Stewart and Muller 2009) provided effective methods for building student teacher knowledge and understanding of, for example, the complex nature of relationships between people and environment (Stewart and Muller 2009). The effect is reported to be more transformative when the place- 
based activities are experienced through different frames (Preston and Griffiths 2004). For instance, for Kulnieks, Longboat and Young (2016) storytelling provided opportunity for reflection. For Preston (2011) storytelling in the form of an 'ecological crisis narrative' (p. 371) added a critical dimension that helped shift students' perceptions and resulted in a deeper understanding of human-nature relationships. According to Preston and Griffiths (2004), journaling is useful for developing capacity for critical thinking and questioning, while discussions enhance students' reflective skills. Lastly, for Collins-Figueroa (2012) futures visioning facilitated motivation and provided 'a moral purpose to harness their [students] energy in planning and working to overcome the challenges they faced' (p. 263).

In summing up the findings, our review finds that teacher educators adopt a comprehensive range of sustainability pedagogies, as well as other pedagogical methods not captured to date in the EfS scholarship. It is not possible, however, to comment on the effectiveness of these methods as authors describe rather than evaluate the methods used. Any attempts to evaluate are founded on nuanced observations rather than empirical evidence. The majority of teacher educators' strategies address all three of Sipos et al's (2008) domains: Cognitive (head) through activities such as critical reflections, affective (heart) through activities like role plays and simulations, and psychomotor (hands) through fieldwork and experiential learning activities. We found that regardless of the pedagogy used, most learning aligned with Sterling's (2011) first order type learning, resulting in enhanced student knowledge, understanding and awareness of sustainability related issues, curriculum and/or pedagogy. A small number of studies reported second order type learning whereby, for example, students' experience a shift of environmental ethic and consciousness as a result of the learning. No studies reported learning of the third order type. In our exploration of emergent 
opportunities, challenges or considerations related to the application of sustainability pedagogies, it is possible to surmise that teacher educators are drawing on an extensive range of pedagogical methods for teaching EfS. In what follows, we consider the implications of our findings.

\section{Discussion and implications}

This systematic review has provided an analysis of pedagogical methods utilised by a small sample of teacher educators to teach EfS. In considering the three questions that guided the review, together with the findings, we now present implications for teaching, learning and researching sustainability through two propositions and a recommendation.

The first proposition is that sustainability pedagogies are widely applied by teacher education academics, but their effectiveness is under researched and under evaluated. Documented examples where pedagogy is at the centre of the research and where the research provides examples of empirically evaluated studies on sustainability pedagogies are limited. While all papers in this review provided details of pedagogical methods applied for teaching EfS, pedagogy was not the focus of most studies.

Pedagogy is described primarily to provide contextual background rather than as a focus of the study. In the few cases where pedagogy is the focus of the study (Burke \& CutterMackenzie, 2010; Preston \& Griffith, 2004; Stewart \& Müller, 2009) evaluation is too nuanced and based on short-term outcomes, thus not giving the reader a clear indication of what does and does not work over time. Robust, long-term evaluation is critical for generating evidence that can be tested and critiqued if research is to inform practice. It is one thing to evaluate intervention outcomes immediately or soon after the intervention. It is another thing to see what teachers actually transfer to the classroom once graduated. Our intent here is not to criticise, but to highlight gaps to inform future 
growth in the field. In this vein, we emphasise a need for long-term, empirically grounded and evaluated research into sustainability pedagogies.

That sustainability pedagogies are widely used by teacher education academics is in contrast to research findings by Cotton and Winter (2010), Cotton, Bailey, Warren and Bissell (2009) and to Christie, Miller, Cooke and White's (2012) earlier analysis of research into sustainability pedagogies and teaching of sustainability in higher education generally. They individually found that the dominant pedagogy in higher education is lecturing and that sustainability pedagogies are more 'aspirational' than 'actual' (Cotton et al., 2009, p. 727). Our study, as seen in the 17 articles reviewed, demonstrates a definite shift towards pedagogical innovation, and an understanding of a need to move to a post-positivist approach to pedagogy. Though, it should be noted the findings of this study are based on reports of self-practice. We are not able to comment on whether or the extent to which innovative pedagogies are replacing teacher-centred strategies such as lecturing. However, in agreement with the above researchers, as well as our own previous work (Author, 2017), the teacher educators in this study offer limited critical reflection or evaluation of pedagogical strategies and approaches for developing knowledge, skills, values and dispositions required to be transformative. This reconfirms the need for more robust research to test and evaluate theory related to sustainability pedagogies. Descriptive studies of practice are useful for generating hypothesis in a field in the early stages of development, however, we argue that robust intervention and evaluation research is necessary for providing data and evidence in order to facilitate positive change in the field (Sanson-Fisher et al. 2006).

Our second proposition is that EfS, and sustainability pedagogies more specifically, represents a wicked problem. This is because teaching and learning and sustainability issues are complex in their own right, difficult to define, and fail to lend 
themselves to clear and simple short-term solutions (Kameniar, Imtoual, and Bradley 2010). There are no universal, short-term strategies for developing student understanding or for overcoming sustainability issues. This review reflects that for teacher educators, it is relatively easy to devise a range of pedagogies for teaching EfS. However, the extent to which these are applicable across a range of contexts is unknown. It is much more difficult to map pedagogical innovation against student needs, sustainability curriculum requirements and learning outcomes over time and across a cohort of students, particularly within an ever-changing context.

We agree that sustainability pedagogies are 'simply good pedagogy' (Higher Education Funding Council for England [HEFCE] 2008) and emphasise this is not a criticism of the pedagogies or their potential. However, based on the studies reviewed here, it is clear that employing sustainability pedagogies per se is not enough to result in transformational learning (Sterling, 2011). Our analysis of the articles denotes that learning outcomes for courses where teacher educators employ sustainability pedagogies are mostly of the first order kind, indicating little effect on pre-service teachers' capacity to make changes for or towards sustainability. We did identify four publications where some second order learning was evident (Preston, 2011; Preston \& Griffith, 2004; Burke \& Cutter-Mackenzie, 2010; Collins-Figueroa, 2012). This is a positive finding that provides optimism for what can be achieved and reflects understanding by some teacher educators about the importance of learning outcomes that reach beyond increasing knowledge and understanding. Nevertheless, even when teacher educators employ a range of creative pedagogies, student learning outcomes are mostly of the first order level with evaluation taking place directly following the intervention. This points to the complex nature of teaching and learning, to the contexts within which pedagogy functions and reflects that transformative learning requires time 
and energy and can be affected by multiple variables (De Boer et al. 2013; Hattie 2009). Hence, this is a further call for long-term empirical and evaluative research into sustainability pedagogies, capable of accounting for contextual complexities over time. Accounting for complexities may require new ways of thinking about how we research sustainability pedagogies in ways that enable us to consider 'not what is the situation, but how it is situated' (Grint 2005, 1471). In other words, we recommend adopting a more holistic approach to pedagogy that considers the broader context around the teaching and learning experiences. This may include, for example, researching learning over time, a series of courses or a whole program rather than just one course, as is the case for studies included in this review.

Finally, in considering further development of sustainability pedagogies, we argue that more attention be paid to the broader Education research base. Current research in sustainability pedagogies is informed by scholarship on the philosophical and ideological underpinnings of teaching and learning (see, for example, Christie et al. 2012), but fails to take advantage of research scholarship from the Education field. We contend that capitalising on robust educational research such as that undertaken by Hattie (2015), Hattie and Donoghue (2016) or Marzano (2009) into effective or high yield teaching strategies, as well as other research that recognises the complexities of teaching and learning (e.g., Deslauriers et al. 2019), may provide a way to more precisely inform, measure and evaluate the impact and effectiveness of sustainability pedagogies. Hattie $(2009 ; 2012)$ and Hattie and Donoghue's (2016) work aims to identify what works best in education through meta-analysis (Hattie, 2009; 2012) of research relating to influences on student achievement and meta-synthesis (Hattie \& Donoghue, 2016) of research linking learning strategies to outcomes. While Hattie's work does have critics (e.g., Bergeron 2017; Slavin 2018), it offers a level of 
interpretation and comprehension capable of extending current insights. It can also provide new approaches for improving current synthesis of studies and, thereby, strengthen the existing sustainability pedagogies evidence-base. Meta-analysis are useful for pooling data across a range of studies that, by themselves, are too small to allow for secure conclusions (Hoffman 2015; Grant and Booth 2009). Meta-synthesis are useful for building theory and for explaining why an intervention works or not (Chrastina 2018). In summary, more robust evaluation will support further learning, capable of advancing current understanding and, ultimately, lead to better outcomes related to learning for sustainability. Last, sustainability pedagogies promote a type of pedagogy that infers a particular or predetermined way of learning. Instead, we call for open and inclusive pedagogical methods that are flexible enough to be inclusive of many different ways of learning.

\section{Conclusion:}

The literature in support of sustainability pedagogies assumes that there is a particular type of pedagogy that is most effective for achieving third-order, epistemic or transformational learning. Our study findings do not support this supposition. The evidence from the studies in this review suggests that even when teacher educators apply sustainability pedagogies, as described by Cotton and Winter (2010) and Sterling (2012), learning outcomes fall short of what the field espouses. Given that the field of EfS/ESD places such high value on pedagogy for learning for sustainability, there is a surprisingly limited exploration or empirical research of what that means, what it looks like, and how effective such strategies are. We argue that greater attention needs to be paid to the pedagogical specificities that enable learning for sustainability. Without this, we will remain wedded to our assumptions about the transformative nature of sustainability pedagogies, without knowing whether or not they are, in reality, effective. 
References

Aleixandre, Maria Pilar Jimenez, and Isabel Garcia-Rodeja Gayoso. 1996. "An Approach to Introducing Environmental Education into the Science Methods Course in Teacher Education." Environmental Education Research 2 (1):27-39.

America, C. 2014. "Integrating sustainability into business education teacher training." South African Journal of Education 34 (3).

Amster, Randall. 2014. "Teaching to the Test: Climate Change, Militarism, and the Pedagogy of Hopefulness." Journal of Peace Education 11 (3):267-78.

Barth, M, Gerd Michelsen, and Marco Rieckmann. 2016. "Routledge handbook of higher education for sustainable development." In. New York: Routledge.

Bergeron, P-J. 2017. "How to engage in pseudoscience with real data: A criticism of John Hattie's arguments in visible learning from the perspective of a statistician." McGill Journal of Education 52 (1).

Blake, Joanna, Stephen Sterling, and Ivor Goodson. 2013. "Transformative learning for a sustainable future: An exploration of pedagogies for change at an alternative college." Sustainability 2013 (5):5347-72. doi: 10.3390/su5125347.

Bowles, T V, and K A Brindle. 2017. "Identifying facilitating factors and barriers to improving student retention rates in tertiary teaching courses: a systematic review." Higher Education Research \& Development 36 (5):903-19. doi: 10.1080/07294360.2016.1264927.

Burke, Geraldine, and Amy Cutter-Mackenzie. 2010. "What's There, What If, What Then, and What Can We Do? An Immersive and Embodied Experience of Environment and Place through Children's Literature." Environmental Education Research 16 (3):20.

Ceulemans, Kim, and M De Prins. 2010. "Teacher's manual and method for SD integration in curricula." Journal of Cleaner Production 18 (2):645-51. doi: 10.1016/j.jclepro.2009.09.014.

Chrastina, Jan. 2018. "Meta-synthesis of qualitative studies: Background, methodoloy and applications." In NORDSCI Conference on Social Sciences. Helsinki, Finland: Saima Consult Limited.

Christie, Belinda A, Kelly K Miller, Raylene Cooke, and John G White. 2012. "Environmental sustainability in higher education: how do academics teach?" Environmental Education Research 19 (3):385-414. doi: 10.1080/13504622.2012.698598.

Christie, Belinda A., Kelly K. Miller, Raylene Cooke, and John G. White. 2013. "Environmental sustainability in higher education: How do academics teach?" Environmental Education Research 19 (3):385-414. doi: http://dx.doi.org/10.1080/13504622.2012.698598.

Clarke, Maggie, and Sharon Pittaway. 2014. Marsh's becoming a teacher. 6th ed. Frenchs Forest, NSW: Pearson Australia.

Collins-Figueroa, Marceline. 2012. "Biodiversity and Education for Sustainable Development in Teacher Education Programmes of Four Jamaican Educational Institutions." Journal of Education for Sustainable Development 6 (2):253-67. doi: http://dx.doi.org/10.1177/0973408212475257.

Cotton, D, I Bailey, M Warren, and S Bissell. 2009. "Revolutions and second-best solutions: education for sustainable development in higher education." Studies in Higher Education 34 (7):719-33.

Cotton, D, and Jennie Winter. 2010. "'It's not just bits of paper and light bulbs': A review of sustainability pedagogies and their potential for use in higher education." In Sustainability education: Perspectives and practice across higher 
education, edited by P Jones, D Selby and Stephen Sterling, 39-54. London: Earthscan.

Curzon, L B. 1997. Teaching in further education: An outline of principles and practice. 5th ed. London: Cassell.

De Boer, H, A S Donker-Bergstra, D Daniel, M Kostons, and H Korpershoek. "Effective strategies for self-regulated learning: A meta-analysis." https://www.rug.nl/research/portal/publications/effective-strategies-forselfregulated-learning(d1f3fc2a-a67f-481d-a0c5-248af5580a84).html.

Deslauriers, L , L S McCarty, K Miller, K Callaghan, and G Kestin. 2019. Measuring actual learning versus feeling of learning in response to being actively engaged in the classroom. Paper presented at the Proceedings of the National Academy of Sciences of the United States of America (PNAS) 2019.

Eggen, P, and D Kauchak. 2012. Strategies and models for teachers. 6th ed. Boston, MA: Pearson.

Eilam, E., and T. Trop. 2011. "ESD Pedagogy: A Guide for the Perplexed." Journal of Environmental Education 42 (1):43-64. doi: 10.1080/00958961003674665.

Grant, M J, and A Booth. 2009. "A typology of reviews: an analysis of 14 review types and associated methodologies." Health Information and Libraries Journal 26 (2):91-108. doi: 10.1111/j.1471-1842.2009.00848.x.

Grint, Keith. 2005. "Problems,, problems,, problems: The social construction of 'leadership'." Human Relations 58 (11):1467-94. doi: 10.1177/0018726705061314.

Guitart, D, c Pickering, and J. Byrne. 2012. "Past results and future directions in urban community gardens research." Urban Forestry \& Urban Greening 11 (2012):364-73. doi: 10.1016/j.ufug.2012.06.007.

Hattie, J. 2009. Visible Learning: A synthesis of over 800 meta-analysis relating to achievement. Abingdon: Routledge.

2015. "The Applicability of Visible Learning to Higher Education." Scholarship of Teaching and Learning in Psychology 1 (1):79-91. doi: $10.1037 /$ st10000021.

Hattie, J, and Gregory M Donoghue. 2016. "Learning strategies: A synthesis and conceptual model." npj Science of Learning 2016 (1):1-13. doi: 10.1038/npjscilearn.2016.13.

Higher Education Funding Council for England [HEFCE]. "Strategic review of sustainable development in higher education in England." HEFCE. http://www.hefce.ac.uk/data/year/2008/hefcestrategicreviewofsustainabledevelo pmentinhighereducationinengland/.

Hines, J M, H R Hungerford, and A N Tomera. 1987. "Analysis and synthesis of research on responsible environmental behavior: A meta-analysis." Journal of Environmental Education 18 (2):1-8.

Hoffman, J I E. 2015. "Meta-analysis." In Biostatics for medical and biomedical practitioners, 645-53. Tiburon, CA: Elsevier Inc.

Hollingsworth, John, and Silvia Ybarra. 2009. Explicit direct instruction: The power of the well-crafted, well-taught lesson. Thousands Oaks, CA: Corin Press.

Hug, J. William. 2010. "Exploring instructional strategies to develop prospective elementary teachers' children's literature book evaluation skills for science, ecology and environmental education." Environmental Education Research 16 (3-4):367-82. doi: http://dx.doi.org/10.1080/13504620903549748.

Hungerford, H, and T Volk. 1990. "Chaning Learner Behaviour through Environmental Education." Journal of Environmental Education 21 (3):8-21. 
Jagger, Susan, Erin Sperling, and Hilary Inwood. 2016. "What's Growing on Here? Garden-Based Pedagogy in a Concrete Jungle." Environmental Education Research 22 (2):271-87.

Jenkins, K. 1999/2000. "Listening to secondary pre-service teachers: implications for teacher education." Australian Journal of Environmental Education 15/16:4556.

Juárez-Nájera, M, H Dieleman, and S Turpin-Marion. 2006. "Sustainability in Mexican higher education: Towards a new academic and professional culture." Journal of Cleaner Production 14 (9-11):1028-38. doi: 10.1016/j.jclepro.2005.11.049.

Kameniar, Barabara Maria, Alia Imtoual, and Debra Bradley. 2010. ""Mullin' the Yearndi" and other wicked problems at a multiracial early childhood educaiton site in regional Australia." Educational Policy 24 (1):9-27. doi: 10.1177/0895904809354321.

Kelly, Peter. 2013. "Comparative Pedagogy: making sense of cultural complexity." Research in Comparative and International Education 8 (4):415-27. doi: 10.2304/rcie.2013.8.4.415.

Kennelly, Julie, and Neil Taylor. 2007. "Education for Sustainability for the K-6 Curriculum: A Unit of Work for Pre-Service Primary Teachers in NSW." Australian Journal of Environmental Education 23:3-12.

Kennelly, Julie, Neil Taylor, and T. W. Maxwell. 2008. "Addressing the Challenge of Preparing Australian Pre-Service Primary Teachers in Environmental Education: An Evaluation of a Dedicated Unit." Journal of Education for Sustainable Development 2 (2):141-56.

Killen, Roy. 2007. Effective teaching strategies: Lessons from research and practice. 4th ed. Melbourne, VIC: Thomson. . 2015. Effective teaching strategies: Lessons from research and practice. 7 th ed. Melbourne: Cengage.

Kulnieks, A., D. R. Longboat, and K. Young. 2016. "Engaging eco-hermeneutical methods: Integrating Indigenous and environmental curricula through an ecojustice-arts-informed pedagogy." AlterNative 12 (1):43-56. doi: 10.20507/AlterNative.2016.12.1.4.

Laurillard, D. 2002. Rethinking university teaching: a framework for the effective use of learning technologies. 2nd ed. London: Routledge Falmer.

Lee, J, and H Choi. 2017. "What affects learner's higher-order thinking in technologyenhanced learning environments? The effects of learner factors." COMPUTERS \& EDUCATION 115 (2017):143-52. doi: 10.1016/j.compedu.2017.06.015.

Lemons, P P, and J D Lemons. 2013. "Questions for Assessing Higher-Order Cognitive Skills: It's Not Just Bloom's." CBE-Life Sciences Education 12 (1):47-58. doi: 10.1187/cbe.12-03-0024.

Littledyke, M, and E Manolas. 2010. "Ideology, epistemology and pedagogy: Barriers and drivers to education for sustainability in science education." JOURNAL OF BALTIC SCIENCE EDUCATION 9 (4):285-301.

Lotz-Sisitka, Heila, Arjen E J Wals, David Kronlid, and Dylan McGarry. 2015. "Transformative, transgressive social learning: rethinking higher education pedagogy in times of systemic global dysfunction." Current Opinion in Environmental Sustainability 16 (October 2015):73-80. doi: 10.1016/j.cosust.2015.07.018. 
Loughran, John. 2013. "Pedagogy: Making sense of the complex relationship between teaching and learning." Curriculum Inquiry 43 (1):118-41. doi: 10.1111/curi.12003.

Luke, A. "Direct Instruction is not a solution for Australian school." www.aare.edu.au/blog/?tag=allan-luke.

Marcinkowski, T. 2004. "Using a logic model to review and analyze an environmental education program." In. Washington, DC: North American Association for Environmental Education.

Marzano, Robert. 2009. "Setting the Record Straight on "High-Yield" Strategies." The Phi Delta Kappan 91 (1):30-7.

McKeown, R. 2012. "Teacher education 1992 and 2012: Reflecting on 20 years." Journal of Education for Sustainable Development 6 (1):37-41. doi: 10.1177/097340821100600109.

McMullen, F, and A Madelaine. 2014. "Why is there so much resistance to Direct Instruction?" Australian Journal of Learning Difficulties 19 (2):137-51.

Mezirow, J. 2009. "Transformative learning theory." In Transformative learning in practice: Insights from community, workplace, and higher education, edited by $\mathrm{J}$ Mezirow, E W Taylor and Associates, 18-31. San Francisco: John Wiley \& Sons Inc.

Mezirow, J \& Associates. 2000. Learning as transformation. San Francisco: JosseyBass.

Nicholas, J, C Oulton, and W Scott. 1993. "Teacher education for the environment: a comparative view from Australia and the UK." International Journal of Science Education 15 (5):564-7.

Oxman, Andrew D, and Gordon H Guyatt. 1993. "The science of reviewing research." Annals of the New York Academy of Sciences 1993 (703):125-34. doi: 10.1111/j.1749-6632.1993.tb26342.x.

Paige, Kathryn, David Lloyd, and Mike Chartres. 2008. "Moving towards Transdisciplinarity: An Ecological Sustainable Focus for Science and Mathematics Pre-Service Education in the Primary/Middle Years." Asia-Pacific Journal of Teacher Education 36 (1):19-33.

Petticrew, Mark, and Helen Roberts. 2006. Systematic Reviews in the Social Sciences: A Practical Guide. Malden, USA: Blackwell Publishing.

Prescott, Debbie. 2016. "Telling Reflections: Teaching Sustainably in a Complex Learning Environment." Australian Journal of Environmental Education 32 (1):80-90. doi: http://dx.doi.org/10.1017/aee.2016.2.

Preston, Lou. 2011. "Green pedagogy - guidance and doubt in teaching Outdoor and Environmental Education." Asia - Pacific Journal of Teacher Education 39 (4):367.

Preston, Lou, and Amma Griffiths. 2004. "Pedagogy of Connections: Findings of a Collaborative Action Research Project in Outdoor and Environmental Education." Australian Journal of Outdoor Education 8 (2):36-45.

Redman, Aaron, and Erin Redman. 2017. "Is subjective knowledge the key to fostering sustainable behavior? Mixed evidence from an education intervention in Mexico." Education Sciences 7 (1):1-38. doi: 10.3390/educsci7010004.

Redman, Erin. 2013. "Advancing Educational Pedagogy for Sustainability: Developing and Implementing Programs to Transform Behaviors." International Journal of Environmental and Science Education 8 (1):1-34.

Richardson, Greer M, Ling L Liang, and Donna G Wake. 2014. "Examining the durability of environmental education self-efficacy beliefs in preservice 
teaching." Applied Environmental Education and Communication 13 (1):38-47. doi: 10.1080/1533015X.2014.913963.

Rickinson, Mark. 2001. "Learners and Learning in Environmental Education: A critical review of the evidence." Environmental Education 7 (3):207-320. doi: 10.1080/13504620120065230.

Sanson-Fisher, Robert W, Elizabeth Campbell, Janice J Perkins, Steve V Blunden, and Bob B Davis. 2006. "Indigenous health research: a critical review of outputs over time." The Medical Journal of Australia (MJA) 184 (10):502-5.

Seatter, Carol Scarff, and Kim Ceulemans. 2017. "Teaching sustainability in higher education: Pedagogical styles that make a difference." Canadian Journal of Higher Education 47 (2):47-70.

Segalàs, J, D Ferrer-Balas, and K F Mulder. 2010. "What do engineering students learn in sustainability courses? The effect of the pedagogical approach." Journal of Cleaner Production 18 (2010):275-84. doi: 10.1016/j.jclepro.2009.09.012.

Segalàs, J, K F Mulder, and D Ferrer-Balas. 2012. "What do EESD “experts" think sustainability is? Which pedagogy is suitable to learn it?" International Journal of Sustainability in Higher Education 13 (3):293-304. doi: 10.1108/14676371211242599.

Shamseer, L, D Moher, M Clarke, D Ghersi, A Liberati, M Petticrew, P Shekelle, L A Stewart, and The PRISMA_P Group. 2015. "Preferred reporting items for systematic review and meta-analysis protocols (PRISMA-P) 2015: Elaboration and explanation." The British Medical Journal 2015 (349):1-23. doi: 10.1136/bmj.g7647.

Sipos, Yona, Bryce Battisti, and Kurt Grimm. 2008. "Achieving transformative sustainability learning: engaging head, hands and heart." International Journal of Sustainability in Higher Education 9 (1):68-86. doi:

10.1108/14676370810842193

Slavin, R. 2018. "John Hattie is wrong." In Robert Slavin's Blog. https://robertslavinsblog.wordpress.com/2018/06/21/john-hattie-is-wrong/.

Sprain, Leah, and William M Timpson. 2012. "Pedagogy for sustainability science: Case-based approaches for interdisciplinary instruction." Environmental Communication 6 (4):532-50. doi: 10.1080/17524032.2012.714394.

Sterling, Stephen. 2010-11. "Transformative learning and sustainability: Sketching the conceptual ground." Learning and Teaching in Higher Education (5):17-33. . 2012. "The Future fit framework: An introductory guide to teaching and learning for sustainability in HE." In. York: The Higher Education Academy.

Stewart, Alistair, and Gregg Muller. 2009. "Toward a Pedagogy for Australian Natural History: Learning to Read and Learning Content." Australian Journal of Environmental Education 25:105-15.

Svanström, Magdalena, Jonas Sjöblom, Jordi Segalas, and Morgan Fröling. 2017. "Improving engineering education for sustainable development using concept maps and multivariate data analysis." Journal of Cleaner Production 198 (2017):530-40. doi: 10.1016/j.jclepro.2018.07.064.

Valentine, J C, A S Hirschy, C D Bremer, W Novillo, M Castellano, and A Banister. 2011. "Keeping at-risk students in school: A systematic review of college retention programs." Educational Evaluation and Policy Analysis 33 (2):21434. doi: 10.3102/0162373711398126.

Westwood, Peter. 2008. What teachers need to know about teaching methods. Camberwell, VIC: ACER Press. 
Wiek, Arnim, Angela Xiong, Katja Brundiers, and Sander van der Leeuw. 2014.

"Integrating problem- and project-based learning into sustainability programs A case study on the School of Sustainability at Arizona State University."

International Journal of Sustainability in Higher Education 15 (4):431-49. doi: 10.1108/IJSHE-02-2013-0013.

Wink, Joan. 2010. Critical pedagogy: Notes from the real world. 4th ed. NY: AddisonWesley Longman Inc. 